\title{
Analysis of Wind Resource Potential for Small-Scale Wind Turbine Performance in Kiseveni, Kenya
}

\author{
Justus Nzuka Mwanzia ${ }^{1,}$, , David Wafula Wekesa ${ }^{2}$, Joseph Ngugi Kamau ${ }^{1}$ \\ ${ }^{1}$ Department of Physics, Jomo Kenyatta University of Agriculture and Technology, Juja, Kenya \\ ${ }^{2}$ Department of Physics, Machakos University, Machakos, Kenya
}

Email address:

nzukajustus@yahoo.com (J. N. Mwanzia),dwekesahit@gmail.com (D. W. Wekesa),k.ngugi.joseph@gmail.com (J. N. Kamau)

${ }^{*}$ Corresponding author

\section{To cite this article:}

Justus Nzuka Mwanzia, David Wafula Wekesa, Joseph Ngugi Kamau. Analysis of Wind Resource Potential for Small-Scale Wind Turbine Performance in Kiseveni, Kenya. International Journal of High Energy Physics. Vol. 6, No. 1, 2019, pp. 17-29.

doi: $10.11648 /$ j.ijhep.20190601.13

Received: February 6, 2019; Accepted: June 17, 2019; Published: June 9, 2019

\begin{abstract}
Kenya's energy depends on fossil fuels and the country is yet to embrace alternative sources especially in densely populated rural areas and urban poor. The use of wind is gaining popularity because it is cost effective, non-polluting, renewable and enormously available. The main challenge is non-availability of the renewable energy resource data in the rural areas where the bulk of the country's population resides. The study assessed wind energy potential for Kiseveni area which is a rural site within expansive Mwingi/Kitui plateau in Kitui. The assessment entailed both empirical and numerical approaches by collecting a ten-minute interval wind speed for a period of six months with sensors elevated at $10 \mathrm{~m}$ height above the ground. From the collected data, wind speed analysis, wind directional analysis, wind energy and power both empirical and numerical was done to establish the available potential of wind energy at the site. In addition, the study elucidated the computational Fluid Dynamics (CFD) application in addressing wind energy potential at the site and its added value with respect to its empirical approach. The results of the study were used to evaluate the potential for wind energy at the site for small-scale wind turbine application to the power-starved population. Empirical power density ranged between $31.65 \mathrm{~W} / \mathrm{m}^{2}$ to $54.00 \mathrm{~W} / \mathrm{m}^{2}$ between $40 \mathrm{~m}$ to $100 \mathrm{~m}$ hub heights respectively with corresponding numerical power density ranging between $71.76 \mathrm{~W} / \mathrm{m}^{2}$ to $125.45 \mathrm{~W} / \mathrm{m}^{2}$. Numerical rotor power $\left(\mathrm{P}_{\mathrm{R}}\right)$ and average wind power $\left(\mathrm{P}_{\mathrm{W}}\right)$ were found to be -0.26 and $33.71 \mathrm{~W} / \mathrm{m}^{2}$ giving a negative $\mathrm{C}_{\mathrm{P}}$ for the height. The results of the study reveal that the site corresponds to wind class 1 meaning the wind resource in the area is not suitable for grid connected generation but can run off grid small wind turbines and stand-alone activities like water pumping.
\end{abstract}

Keywords: SWT, Wind Resource, WPD, Empirical Statistics, CFD

\section{Introduction}

Kenya has for the past 20 years experienced rapid growth of urban centers but still majority of Kenyans reside in rural areas. Due to increased growth in health care, Kenya has also experienced rapid growth rate in population and this has translated to demand for energy increasing at a faster rate than available supply which has led to shortage of primary sources of energy as well as depletion of natural resources capital. Kenya is a developing country with energy mainly derived from wood biomass (68\%), petroleum fuels (22\%) and electricity $9 \%$. [1] These energy sources are environment unfriendly and due to increasing environmental consciousness, a more environment friendly energy sources are needed [2]. This situation is particularly serious in rural areas where most of the population resides. It is estimated that $68 \%$ of inhabitant of sub-Saharan Africa reside in rural areas [3]. There is therefore need to provide modern energy services to this population. Wind energy can be used to enhance access to affordable energy to the rural poor owing to its cost effectiveness, enormity of availability and its nonpolluting nature. Kenya is however yet to embrace this 
technology due to non-availability of the resource data for most parts of the country [2].

It has been shown from a survey that almost $90 \%$ of Kenyans rely on traditional fuels such as biomass, charcoal and dung to meet their heating and cooking needs [3]. Dependence on firewood in the rural areas is on the rise, with more than $80 \%$ of households relying on firewood for cooking compared to $10 \%$ of urban households. Charcoal is the second most popular type of cooking fuel used by $13.3 \%$ of households [1], while kerosene is the third and frequently utilized among $44.6 \%$ of urban dwellers [1]. Decentralized energy systems, particularly systems that use renewable natural resources can offer a solution and, in many cases, the only possible one to supply electricity to isolated areas where the grid cannot reach [2]. Most commonly used renewable energy options for delivering energy in such rural areas are small- scale hydro power plant, wind, solar and biogas technologies [2]. Such hydropower plants have lower efficiency and because of lack of water reservoir, they depend on the hydrological cycle of that location [4]. This makes them least appropriate making wind and solar more appropriate. Wind is available for more hours a day than solar meaning wind is more appropriate to power such areas than any other renewable source. In the latest years, there has been marked exponential growth experienced in the wind sector worldwide. Wind energy has become an indispensable part of the energy mix [1,5] Economic feasibility of particular prospective wind energy is highly site specific, therefore there is need for satisfaction information concerning wind energy resources [2, 5]. As a result, a precise knowledge of wind regime characteristics is a prerequisite for implementation of any wind energy resource. This study capitalizes on above aspects and seeks to provide the missing data; and investigates the feasibility of employing small wind turbine generators (SWTG) for provision of modular power to the arid Kiseveni area of Kitui county in Eastern Kenya.

\section{Methodology}

\subsection{The Experimental Techniques}

Wind speed measurement was done at a tower height level of $10 \mathrm{~m}$, located in Kiseveni area Eastern Kenya. The site is located on latitude $1^{0} 22^{\prime} \mathrm{S}$ and on longitude $38^{0} 02 / \mathrm{E}$. It is at a height of $3433 \mathrm{ft}$ above mean sea level (AMSL), Wind speed data was measured and averaged at an interval of 3 hours for storage in a data logger. The three-hour averaged wind speed data was further averaged to give daily mean and monthly mean for a period of six months.

Wind speeds at higher heights were also calculated using power law. The monthly mean wind speeds were used as mean wind speed, while respective standard deviation $(\sigma)$ averages as fluctuating amplitude $\mathrm{V}_{\text {amp }}$, to represent the wind characteristics of the site. Using power law and already determined wind shear exponent for the area of 0.2 [2], wind speeds at higher heights were extrapolated. The power law as defined in Wekesa et al [1] is;

$$
V_{Z}=V_{1}\left(\frac{Z}{Z_{1}}\right)^{\alpha}
$$

where $V_{z}$ is wind speed at height $z$, and $V_{1}$ is the reference wind speed at reference height $Z_{1}$. The exponent $\alpha$ is empirically derived coefficient that depends on such factors as surface roughness and atmospheric stability.

\subsubsection{Study Site}

The selected Kiseveni area sits on extensive Mwingi/Kitui plateau adjoining coastal belt to the south and north-eastern zones to the east and north of Kenya. The site is located on latitude $1^{0} 22^{\prime} \mathrm{S}$ and on longitude $38^{0} 02^{\prime} \mathrm{E}$. It is at a height of $3433 \mathrm{ft}$ above mean sea level (AMSL).

\subsubsection{Experimental Setup}

The measuring instrument setup included two anemometers, one wind vane and a temperature sensor. The arrangements of the instruments on the mast before it is erected in position are as follows;

a. The anemometer was fitted at $10 \mathrm{~m}$ height above the ground on a horizontal transverse of length $1.0 \mathrm{~m}$ on to which a vertical sensor holder of length $0.3 \mathrm{~m}$. These clearance distances are necessary in order to minimize turbulence and shading effects of wind by the mast and transverse. The instruments were in turn held on the $0.3 \mathrm{~m}$ sensor holders.

b. The wind vane was fixed at about $1.5 \mathrm{~m}$ below the anemometer on the traverse of length $1.0 \mathrm{~m}$ from mast and perpendicular to the appropriate wind direction to minimize turbulence effects due to the rotating speed sensor.

c. A transmitter was held at an angle of $45^{\circ}$ to the approximate wind direction to reduce the interference to transmission by wind.

The measuring instrument setup included two anemometers, one wind vane and a temperature sensor. The arrangement of the instruments on the mast before it is erected in position are as follows;

\subsubsection{Setting up a Measurement Tower}

The setup consisted of a light but rigid triangular metallic tube. The mast was fitted with a lighting arrestor spike and a red aviation warning light at the top. It was firmly held in the vertical position with steel guy wires pinned to the ground in three equilaterally spaced directions for enhanced stability. The measuring instruments setup included one anemometer, one wind vane and temperature probe within the data logger box.

\subsubsection{Measurement Procedures}

After setting up of the mast, the first month was used for calibration and test running of the equipment in readiness for a long-term data collection. Upon getting satisfied that all the instruments were running as expected, data logging commenced. Wind speed was recorded at 3-hour intervals at a height of $10 \mathrm{~m}$ above the ground and subjected to analysis to yield meaningful calculations and interpretations. Wind 
direction was measured at a height of $1.5 \mathrm{~m}$ below the anemometer so as to minimize turbulence effects from the rotating anemometer. The temperature of the surrounding air was $20.4^{0}$.

\subsubsection{Data Analysis}

The input data included wind speeds, temperature and height above sea level. After validation process, data was statistically analyzed to give site specific mean wind speeds at $10 \mathrm{~m}$ and extrapolated using empirical statistics to obtain those at higher elevations.

\subsection{Numerical Techniques}

A monthly average wind speed across six months was used in the numerical model as mean wind speed $v_{\text {mean }}$ while the standard deviations ( $\sigma S)$ monthly averages was used as fluctuating amplitude $v_{a m p}$.

\subsubsection{The Computational Model}

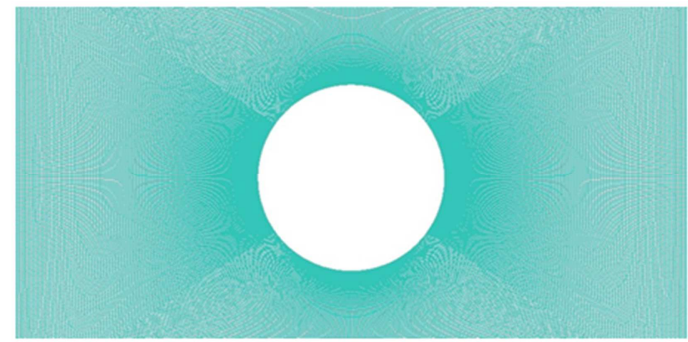

(a). Rotating inner and stationary outer domain meshes

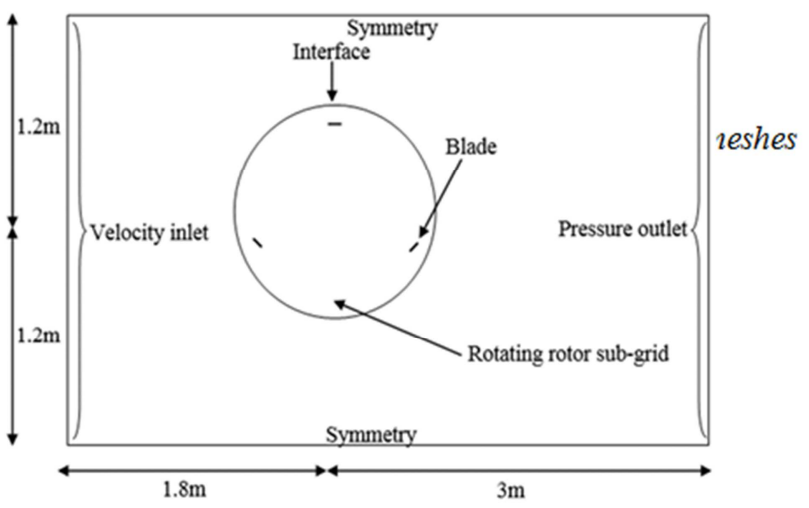

(b). Schematic representation of 2D numerical domain

Figure 1. An illustration of boundary conditions and meshes of $2 D$ numerical domain [1].

A 2D incompressible unsteady CFD software based on finite volume/method in the numerical software package ANSYS FLUENT was employed. Basic analysis procedures that was employed in obtaining a numerical solution on a small wind turbine rotor was divided into 3 steps namely preprocessing, flow field and post processing $[1,5,6]$. As a result, the corresponding basic elements which complete the numerical process in the present study are pre-processor, solver and post-processor respectively. The CFD computational domain has two mesh zones; the inner circular Rotor sub-grid zone and the rectangular outer zone which communicate via a pair of circular interfaces between them [1, 5, 6]. A User-Defined Function (UDF) subroutine was developed and attached to the flow solver to control the dynamic mesh motion. Observe in Figure 2, that the inner Rotor sub-grid zone is composed of three symmetric airfoil blades spaced equally at $120^{\circ}$ apart rotating at a common angular velocity. Following $[1,5,6]$, the blades were defined as no-slip walls, while both interface boundary of the Rotor sub-grid and the outer rectangular wind tunnel sub-grid were set as an interface. No-slip wall boundary condition is used in this simulation to model the bottom and the top sides of the domain [1]. From the wall distance study by Danao et al. [7] and Wekesa et al. [6], the side wall distance was set to $1.2 \mathrm{~m}$ from SWT axis test section (Figure 2). The velocity inlet boundary condition from the test section was set to $1.5 \mathrm{~m}, 0.3$ $\mathrm{m}$ short of the $1.8 \mathrm{~m}$ in Wekesa et al. [1, 5]. The pressure outlet boundary condition was set to $3 \mathrm{~m}$ downwind to match the actual distance of the wind tunnel fan from the SWT axis of rotation [8]. Further details on domain boundary location with mesh and time step independence preliminary studies has been referenced in $[1,5-7,9,10]$.

\subsubsection{Turbulence Model}

The Transition shear stress turbulent (SST) model was used for turbulent calculations, as suggested from recent studies by Wekesa et al $[1,5,6,11,12]$. This was attributable to its well behavior in adverse pressure gradients and separating flow, which were typically seen during the unsteady wind inflow operation on a turbine rotor scale $[1,5$, $6,11,12]$. As a result, in the present study, the Transition SST model was employed for all the successive numerical simulations.

\subsubsection{Computational Cost}

The calculations were performed on a computer having, Intel $^{\circledR}$ Core $^{\mathrm{TM}}$ i7-2600 CPU@3.40 GHz, 4 cores, 8 threads, physical RAM of $8 \mathrm{~GB}$, and Windows 8 professional 64-bit operating system. Each simulation required a total Central Processing Unit (CPU) time of about 5 days.

\section{Results and Discussion}

In the present study, wind velocity was empirically determined at a three-hour interval at $10 \mathrm{~m}$ turbine hub height and then using power law extrapolated to higher turbine hub heights ranging from $20 \mathrm{~m}$ to $100 \mathrm{~m}$. Numerical analysis was also done to yield results which were compared with the empirical data.

\subsection{Wind Speed Analysis}

Wind speed data was collected at $10 \mathrm{~m}$ turbine height for a period of six months from August 2017 to January 2018. Daily and monthly wind speeds were determined. Using the value of shear exponent for the site as $0.20[1$, 2] wind speeds at higher heights of $20 \mathrm{~m}, 40 \mathrm{~m}, 60 \mathrm{~m}, 80$ $\mathrm{m}, 100 \mathrm{~m}$ was determined. Daily mean wind speed charts for each month were plotted as shown in Figure 3. 


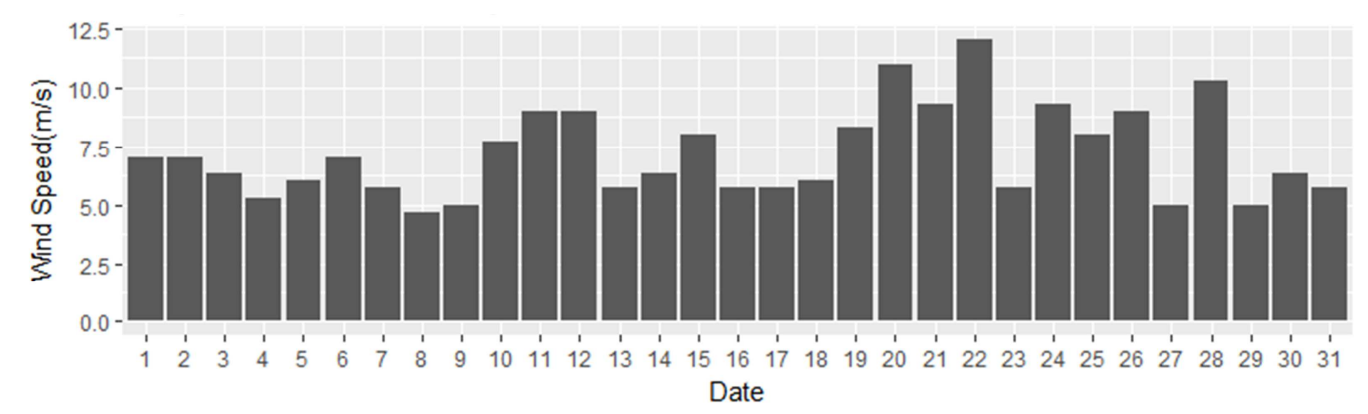

(a). Daily mean wind speed for month of august 2017

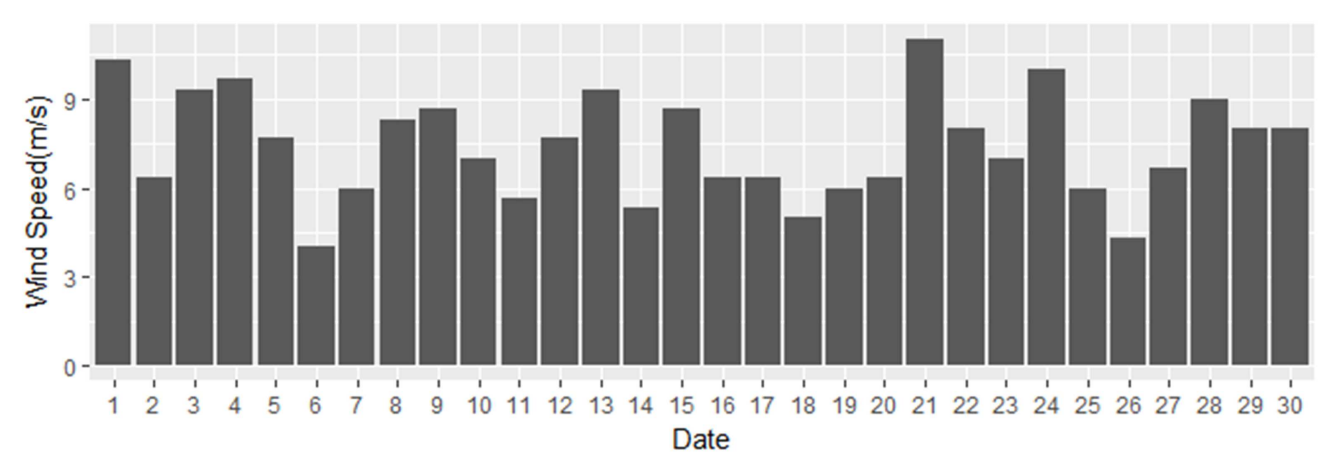

(b). Daily mean wind speed for month of September 2017

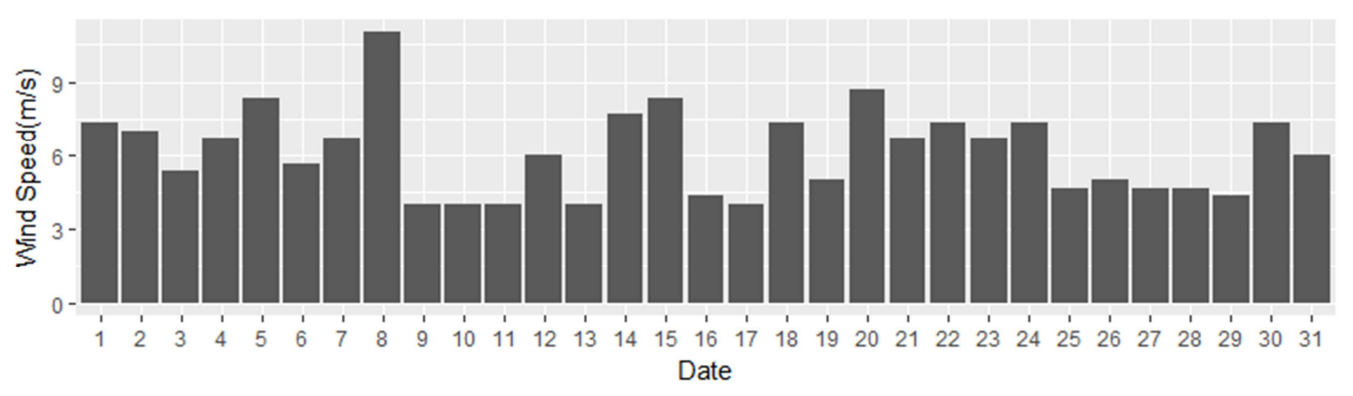

(c). Daily mean wind speed for month of October 2017

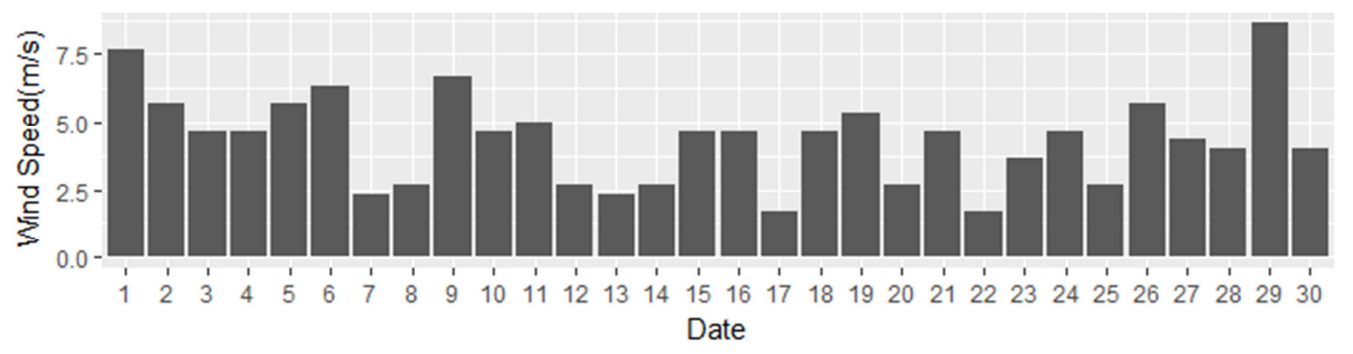

(d). Daily mean wind speed for the month of November 2017

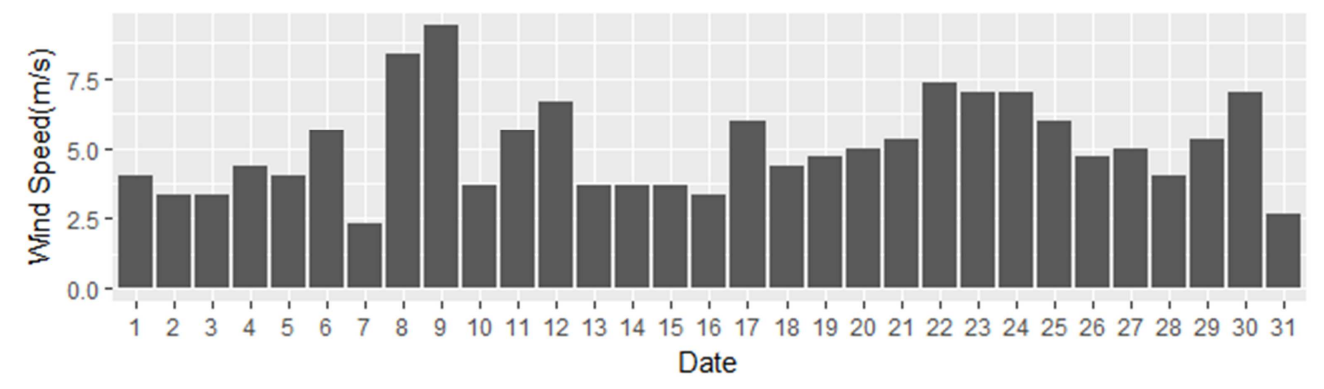

(e). Daily mean wind speed for the month of December 2017 


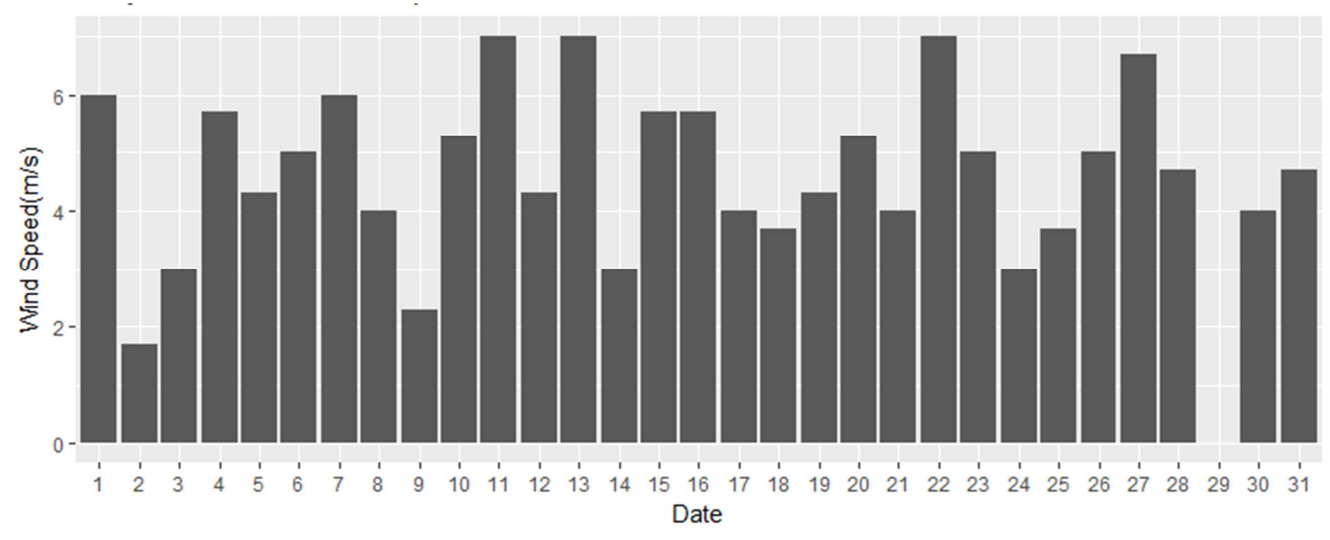

(f). Daily mean wind speed for the month of January 2018

Figure 2. Daily mean wind speeds charts from August 2017 to January 2018.

To enable understand the distribution of wind speeds, wind speed frequency distribution curves were done for each month under study as shown in Figure 4.

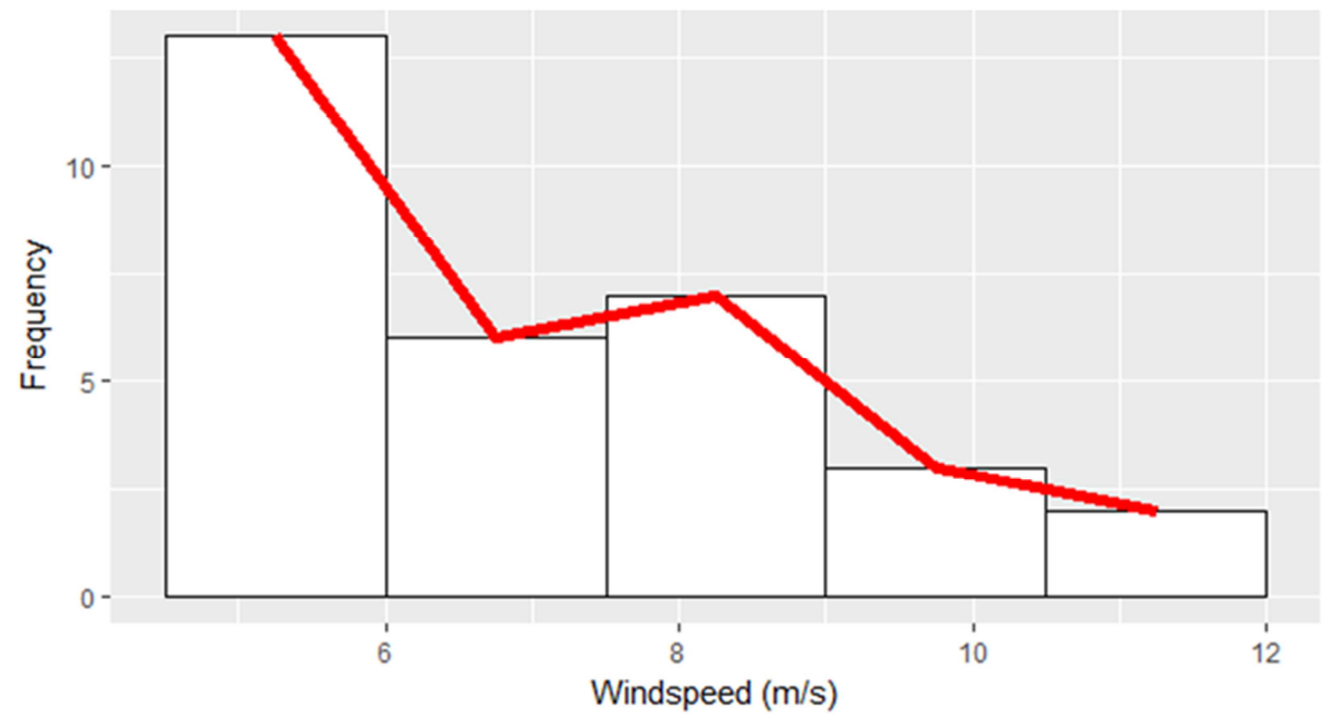

(a). Wind speed frequency distribution for August 2017

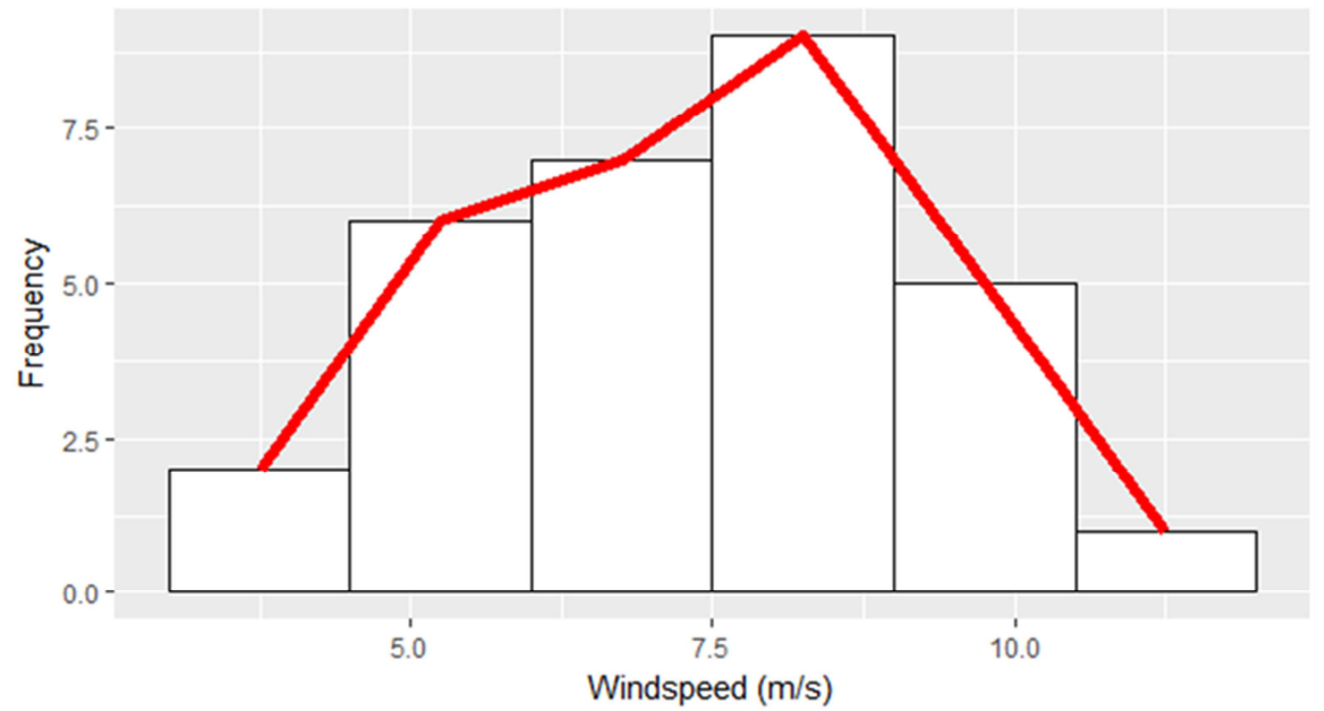

(b). Wind speed frequency distribution for September, 2017 


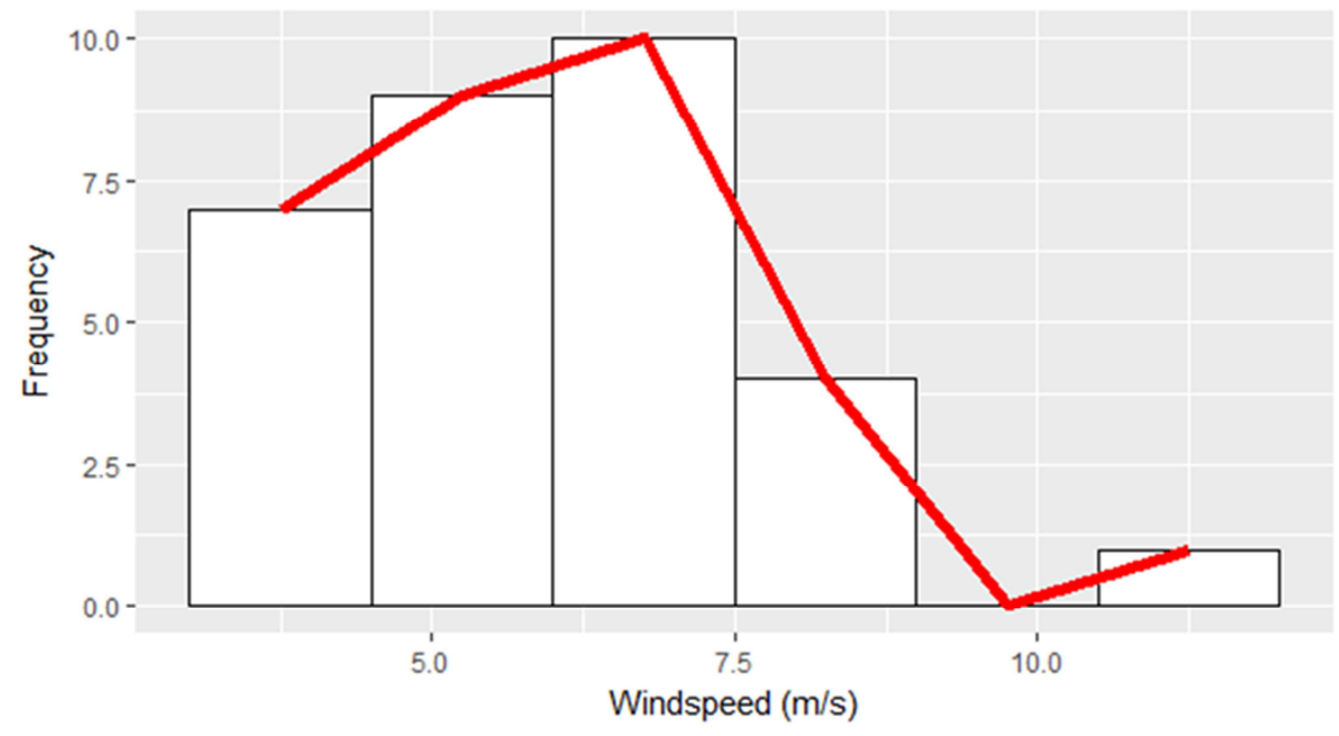

(c). Wind speed frequency distribution for October, 2017

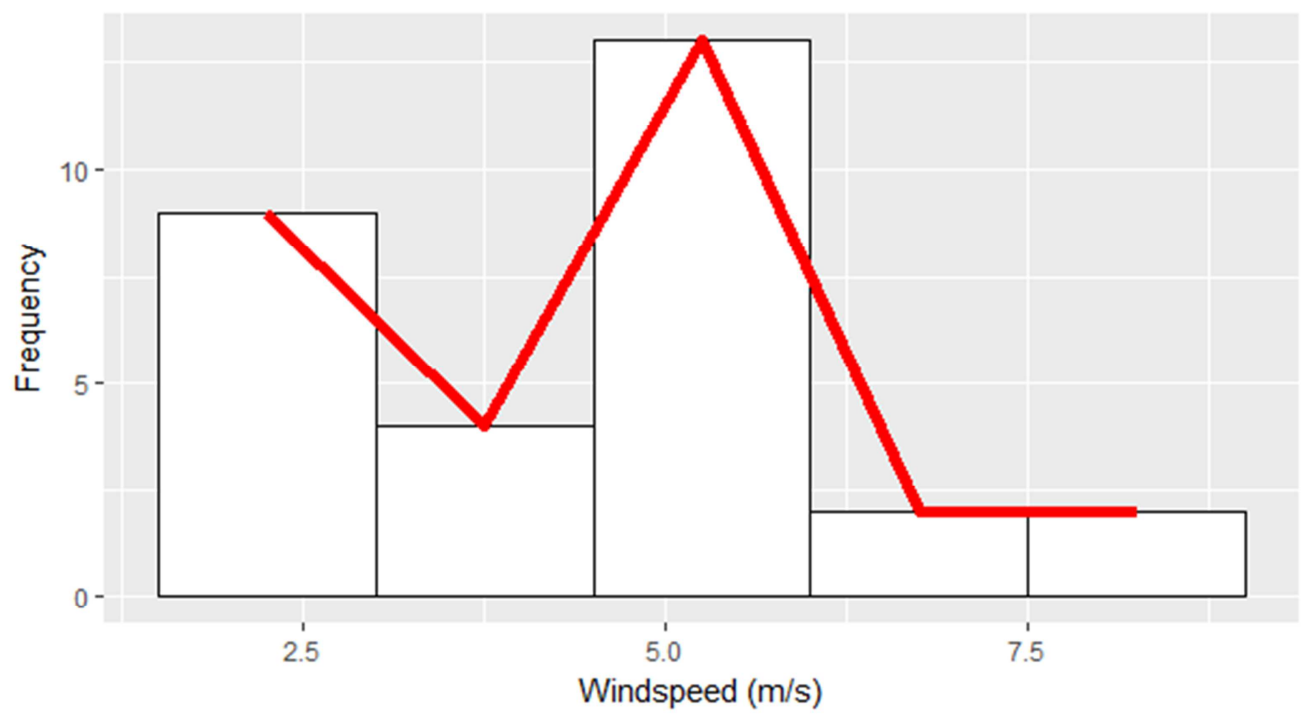

(d). Wind speed frequency distribution for November, 2017

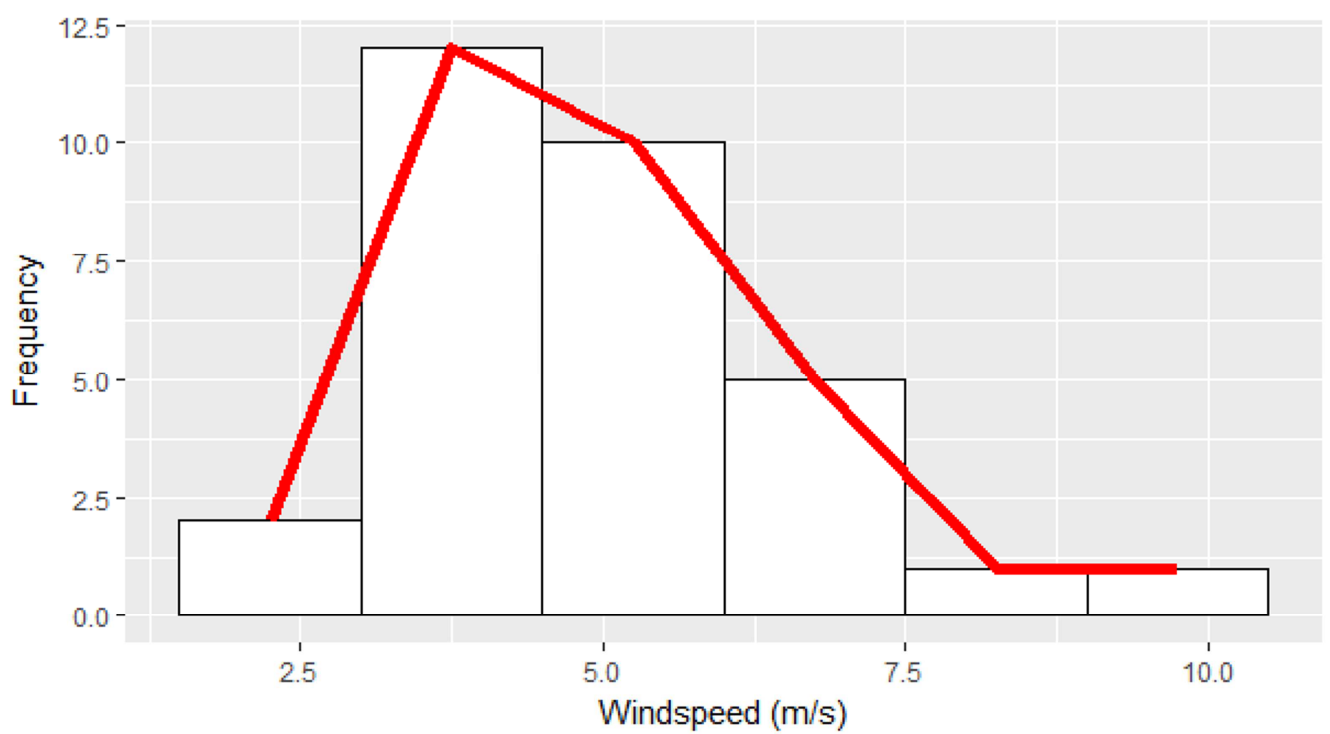

(e). Wind speed frequency distribution for December, 2017 


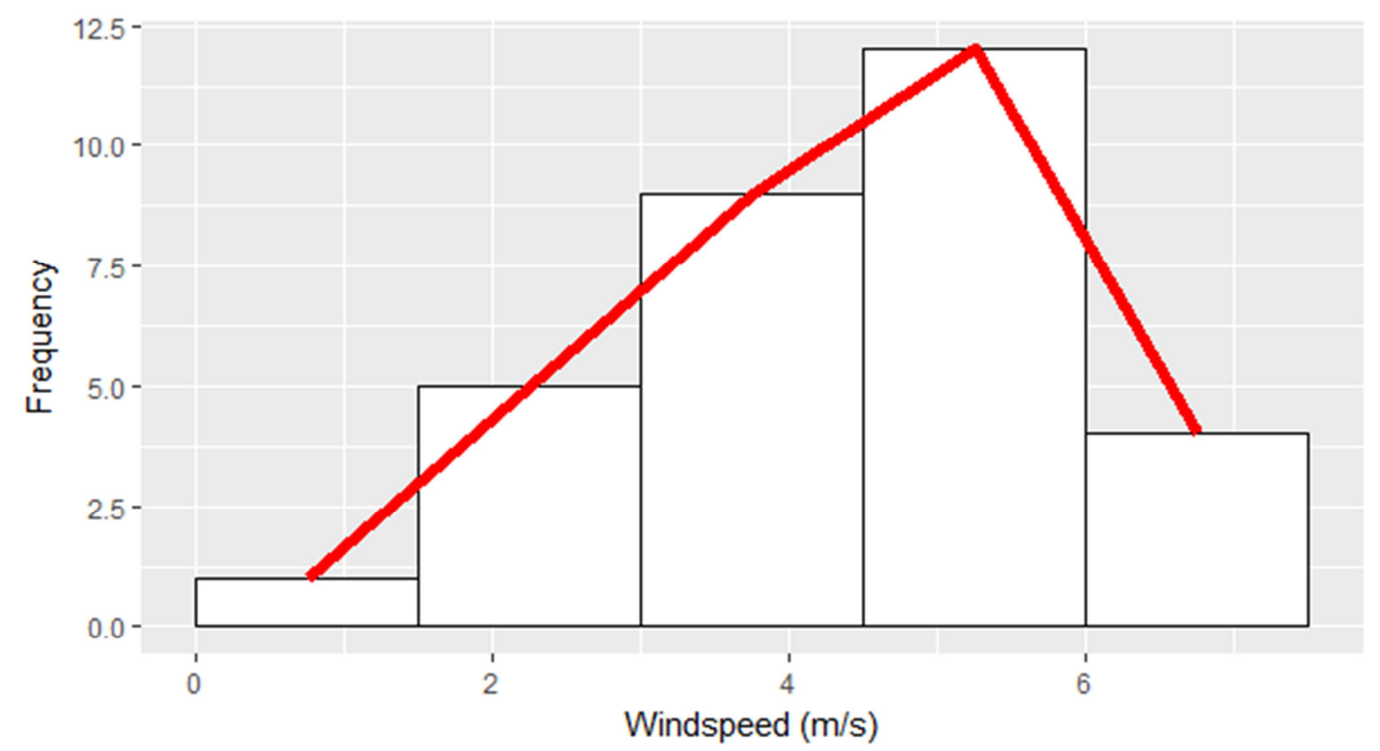

(f). Wind speed frequency distribution for January, 2018

Figure 3. Monthly wind speed frequency distribution curve from August 2017 to January 2018.

In all months under study, a steady wind flow was observed with month of January showing higher daily means. The months of November 2017 and January 2018 recorded low wind speeds. The area wind flow pattern varies with a very small range between subsequent days of the month. This has the advantage of ensuring smooth rotations of wind machines which is always above the 3.5 $\mathrm{m} / \mathrm{s}$ cut in speed for most commercial wind turbines. Using power law, wind speed at higher turbine hub height was also extrapolated.

\subsection{Direction Analysis}

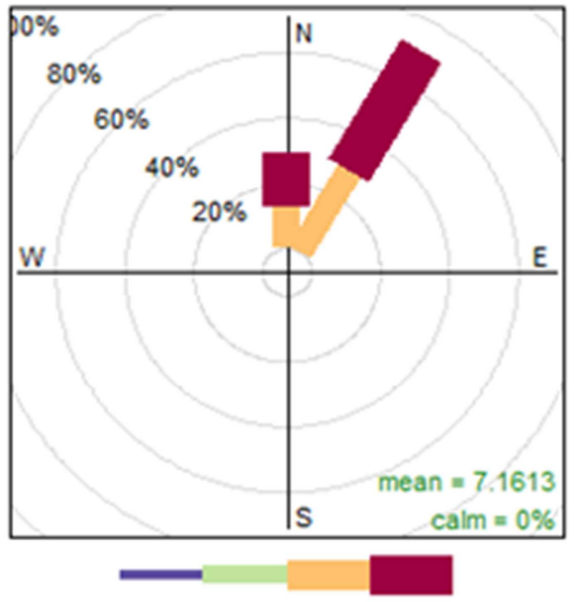

0 to 22 to 44 to 66 to 12

$\left(\mathrm{m} \mathrm{s}^{-1}\right)$

Frequency of counts by wind direction (\%)

(a). Wind rose for August 2017

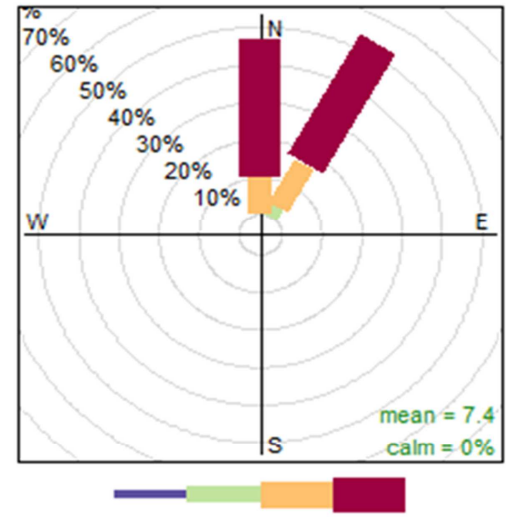

0 to 22 to 44 to 66 to 11 $\left(\mathrm{m} \mathrm{s}^{-1}\right)$

Frequency of counts by wind direction (\%)

(b). Wind rose for September 2017

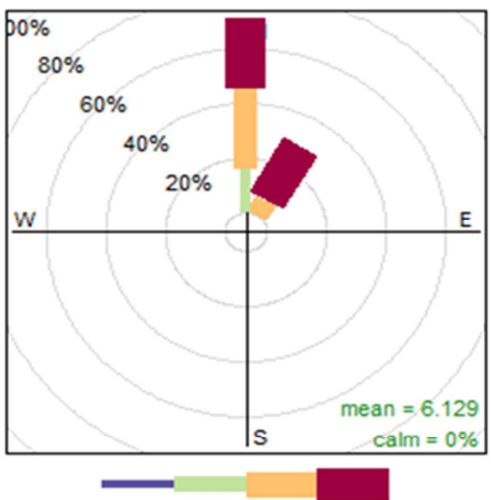

0 to 22 to 44 to 66 to 11

$\left(\mathrm{m} \mathrm{s}^{-1}\right)$

Frequency of counts by wind direction (\%)

(c). Wind rose for October 2017 


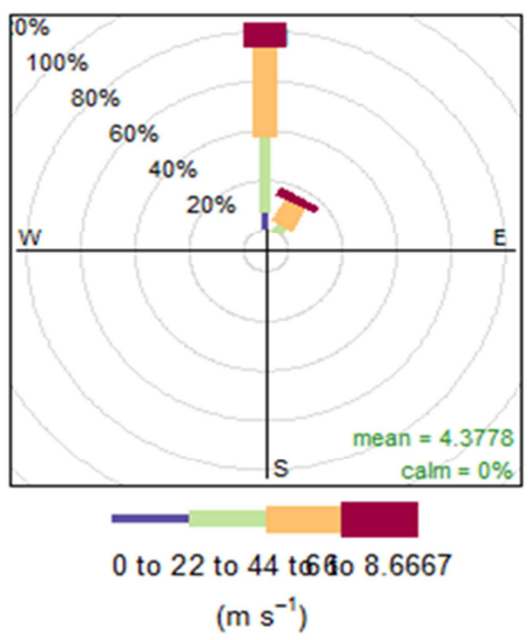

Frequency of counts by wind direction (\%)

(d). Wind rose for November 2017

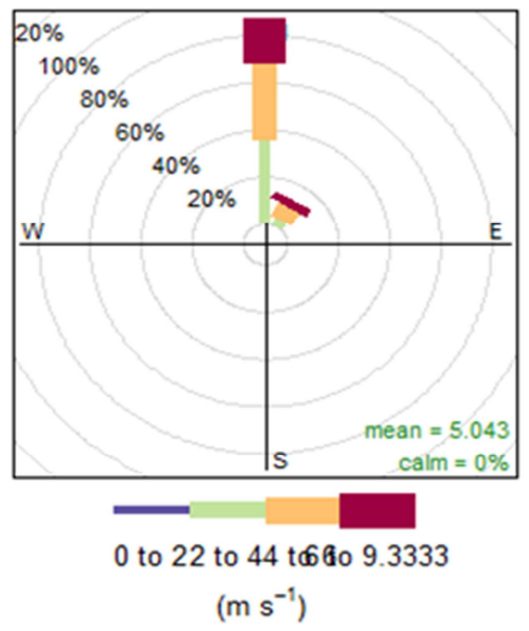

Frequency of counts by wind direction (\%)

(e). Wind rose for December 2017

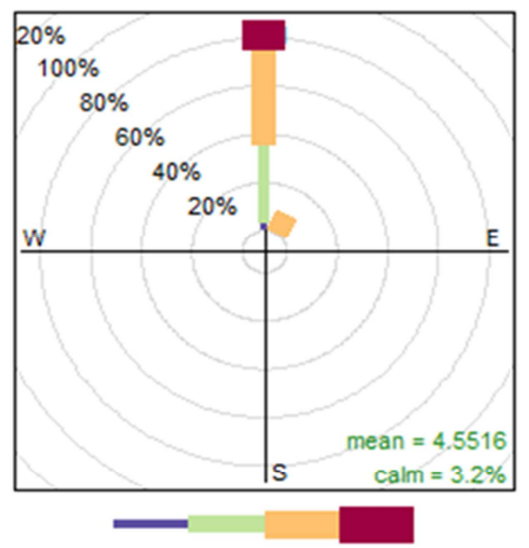

0 to 22 to 44 to 66 to 7 $\left(\mathrm{m} \mathrm{s}^{-1}\right)$

Frequency of counts by wind direction (\%)

(f). Wind rose for January 2018
The most prevalent wind direction in the month of August 2017, September 2017, and October 2017 is SSE with that of November 2017, December 2017 and January 2018 being eastwards. These findings are supported by the NEMA report that south easterly (SE) winds dominate the East Africa region from April to October while the northern easterlies drive the prevailing winds from November to March [2]. The directional behavior of wind is well understood by plotting a wind direction rose which is a tool to demonstrate the percentage of total time that wind flows with a given speed from a particular direction and also the percentage energy content from a particular direction thus giving the percentage of time the system is able to generate useful power. Wind roses were plotted for every month under study as shown in Figure 5.

\subsection{Temperature Analysis}

The highest recorded monthly mean for the period under study was $25.3^{0}$ in the month of January 2018 and the lowest mean was $22.3^{\circ}$ in the month of August 2017. Under the period of study, the site showed a small temp range of between $22.3^{0}$ and $25.3^{0}$. This is an advantage for the operation of wind turbines.

\subsection{Small Wind Turbine Performance}

The calculated values of wind power density (wind power production per square area of a turbine) by the empirical study were compared with those of the numerical method. Higher turbine hub heights were used to give higher wind power densities for practical small-scale harnessing of wind energy. The calculated numerical rotor average power $P_{R}$ and wind average power $\mathrm{P}_{\mathrm{w}}$ ranged from 3.06 to $15.26 \mathrm{~W}$ and 50.23 to $87.83 \mathrm{~W}$ at $40 \mathrm{~m}-100 \mathrm{~m}$ turbine hub heights, respectively. However, at the lowest turbine hub height of 20 $\mathrm{m}$, numerical $\mathrm{P}_{\mathrm{R}}$ and $\mathrm{P}_{\mathrm{w}}$ are $-0.26 \mathrm{~W}$ and $33.71 \mathrm{~W}$, respectively, resulting into a negative power coefficient of 0.01 . The largest positive $\mathrm{CP}$ performance of 0.17 is registered at $100 \mathrm{~m}$ turbine hub height with a highest prevailing mean wind speed of $4.6 \mathrm{~m} / \mathrm{s}$. This is attributable to shorter bursts of high-speed winds (gusts) occurring between the normal wind flow speeds ranging between 4 and $5 \mathrm{~m} / \mathrm{s}$. The averaged numerical wind power density WPD as a function of $\mathrm{P}_{\mathrm{w}}$ over one wind cycle divided by SWT projected area A, defined as [1]

$$
W P D=\frac{P_{W}}{A}=\frac{1}{2} \rho V_{\infty}^{3}
$$

The numerical matches the empirical wind power densities at all turbine hub height elevations, hence confirming the reliability of the results. Table 1 gives the analysis of numerical power performance at various turbine hub heights with Table 2 shows both numerical and empirical power densities with characteristic fluctuating amplitudes at respective fluctuating mean wind speeds. 
Table 1. Numerical power performance.

\begin{tabular}{lllll}
\hline Hub height of turbine $(\mathbf{M})$ & $\mathbf{2 0}$ & $\mathbf{4 0}$ & $\mathbf{6 0}$ & $\mathbf{8 0}$ \\
\hline Mean wind speed $\mathrm{U}_{\text {mean }}(\mathrm{m} / \mathrm{s})$ & 3.30 & 3.85 & 4.15 & 4.35 \\
Fluctuating amplitude $\mathrm{U}_{\mathrm{amp}}(\mathrm{m} / \mathrm{s})$ & 0.90 & 1.15 & 1.30 & 1.30 \\
Power coefficient CP & -0.01 & 0.06 & 0.12 & 0.14 \\
Rotor average power $\mathrm{P}_{\mathrm{R}}(\mathrm{W})$ & -0.26 & 3.06 & 7.65 & 1.30 \\
Wind average power $\mathrm{P}_{\mathrm{W}}(\mathrm{W})$ & 33.71 & 50.23 & 6.17 & $\mathbf{1 0 0}$ \\
\hline
\end{tabular}

Table 2. Empirical and Numerical wind power density.

\begin{tabular}{|c|c|c|c|c|}
\hline \multirow{2}{*}{ Hub height (m) } & \multirow{2}{*}{$\mathbf{U}_{\text {mean }}(\mathbf{m} / \mathbf{s})$} & \multirow{2}{*}{$\mathbf{U}_{\mathrm{amp}(\mathbf{m} / \mathbf{s})}$} & \multicolumn{2}{|c|}{ Wind power density $\left(\mathrm{W} / \mathrm{m}^{2}\right)$} \\
\hline & & & numerical & empirical \\
\hline 20 & 3.30 & 0.90 & 48.16 & 19.93 \\
\hline 40 & 3.85 & 1.15 & 71.76 & 31.65 \\
\hline 60 & 4.15 & 1.30 & 92.24 & 39.64 \\
\hline 80 & 4.35 & 1.30 & 110.11 & 45.66 \\
\hline 100 & 4.60 & 1.30 & 125.45 & 54.00 \\
\hline
\end{tabular}

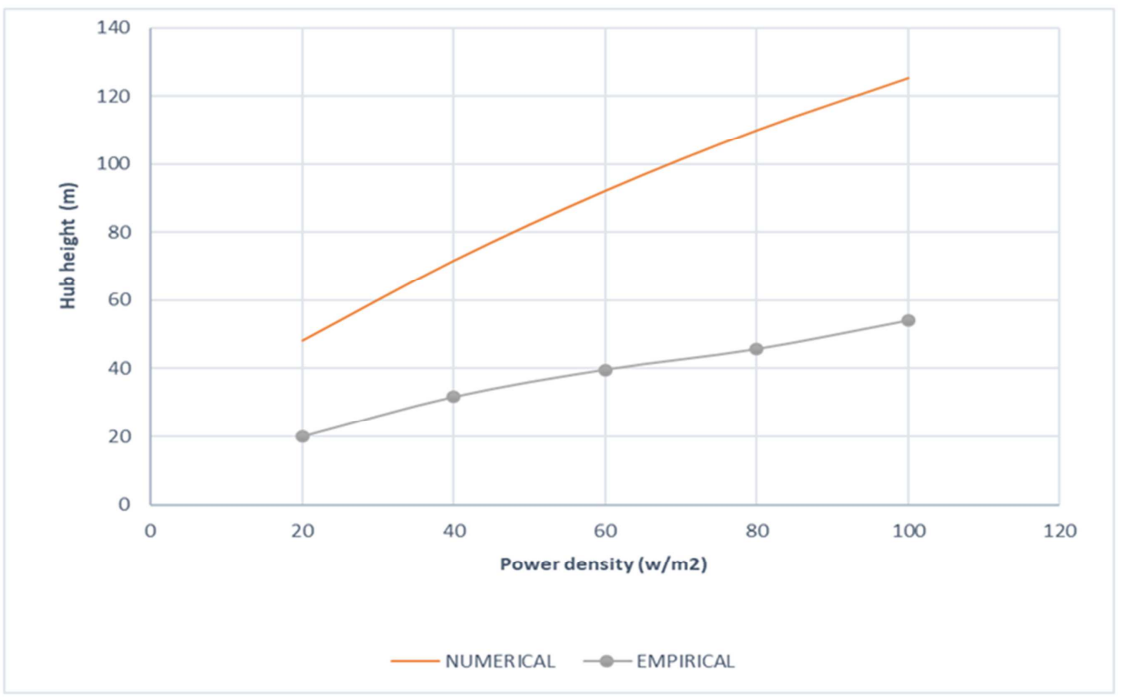

Figure 5. Turbine hub height versus wind power density.

Figure 5 reveals uniform variability of both wind power densities across the turbine hub heights with the numerical power density curve showing slightly higher WPD. This can be attributable to the fact that $2 \mathrm{D}$ vertical axis SWT models are essentially SWTs with infinite blade aspect ratio (AR) which shifts the numerical power density upwards, but the general shape remains the same. $[1,5,7,13,14]$ The air density for the site is $1.132 \mathrm{~kg} / \mathrm{m}^{3}$ based on the temperature and height above sea level, agreeing with the literature findings in $[1,2]$. Furthermore, the minimum to maximum empirical WPD range falls within that of the numerical WPD range across the turbine hub heights.

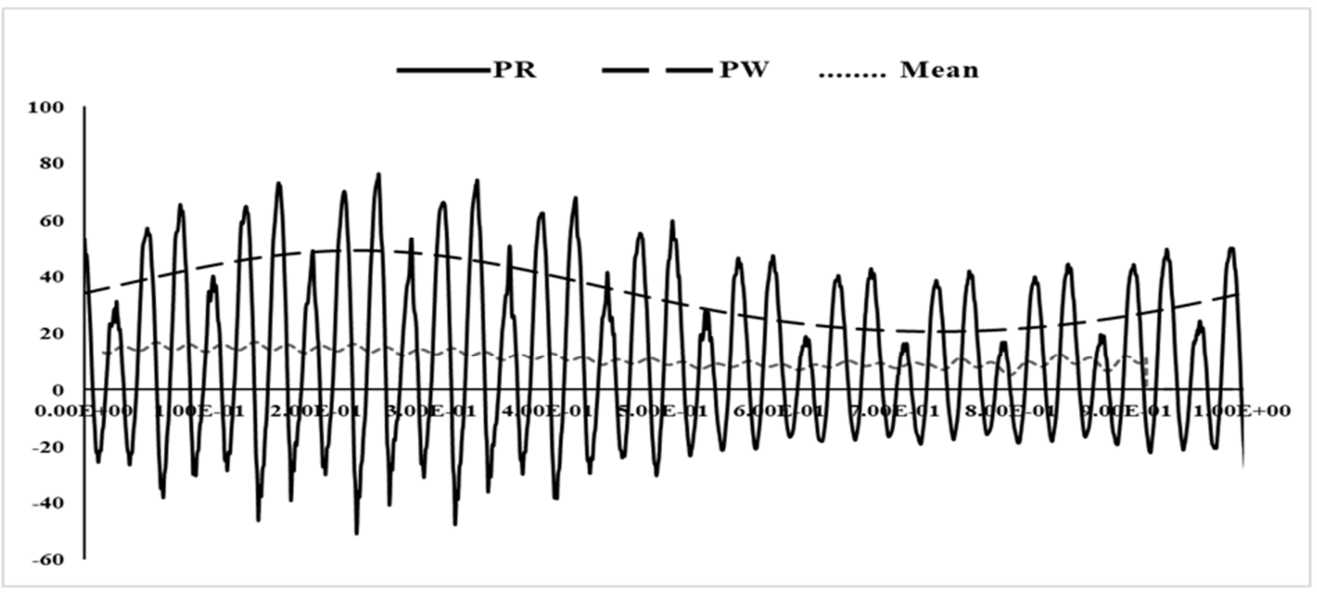

(a). $20 \mathrm{~m}$ turbine hub height 


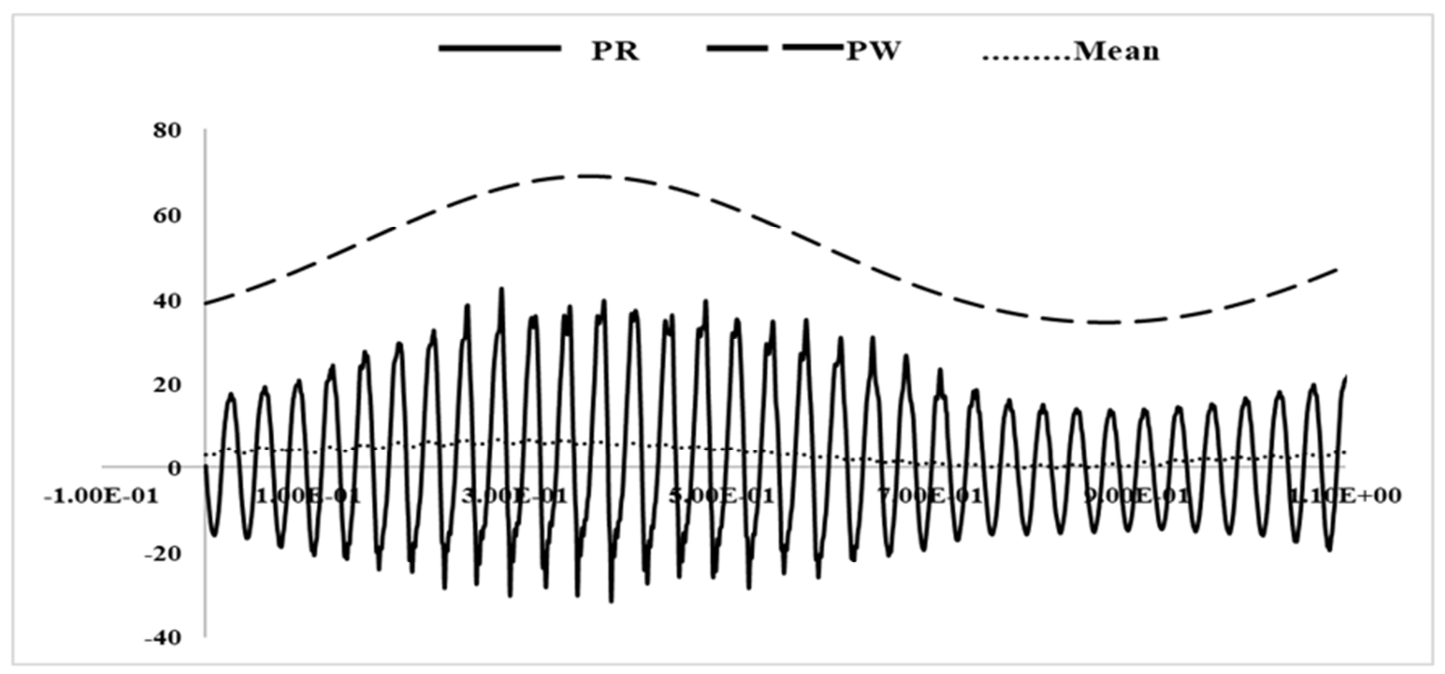

(b). $40 \mathrm{~m}$ turbine hub height

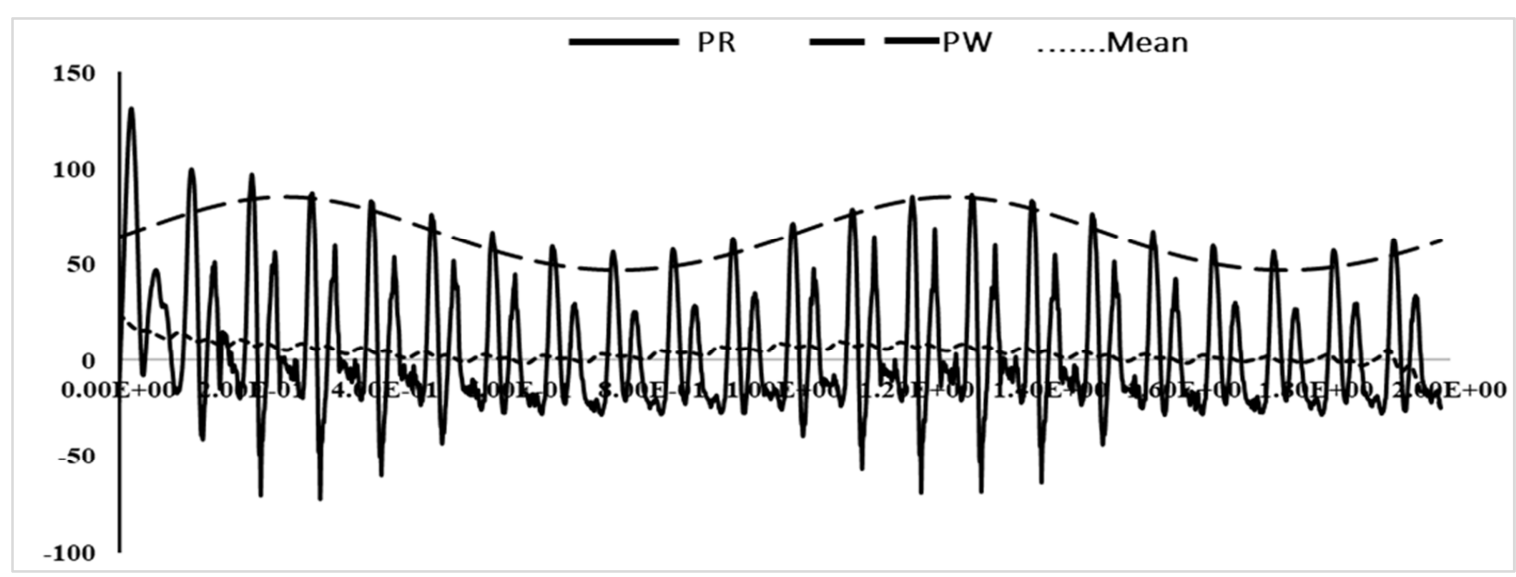

(c). $60 \mathrm{~m}$ turbine hub height

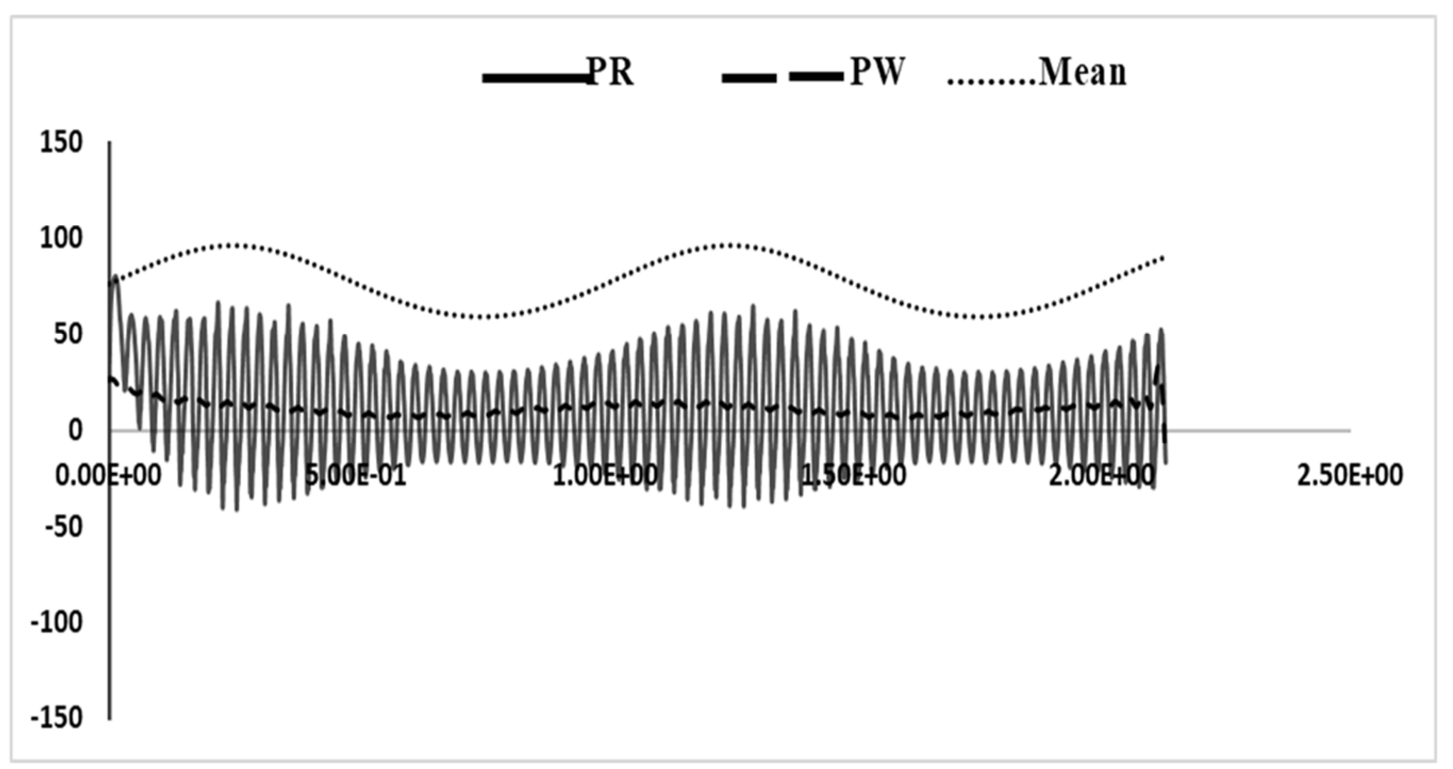

(d). $80 \mathrm{~m}$ turbine hub height 


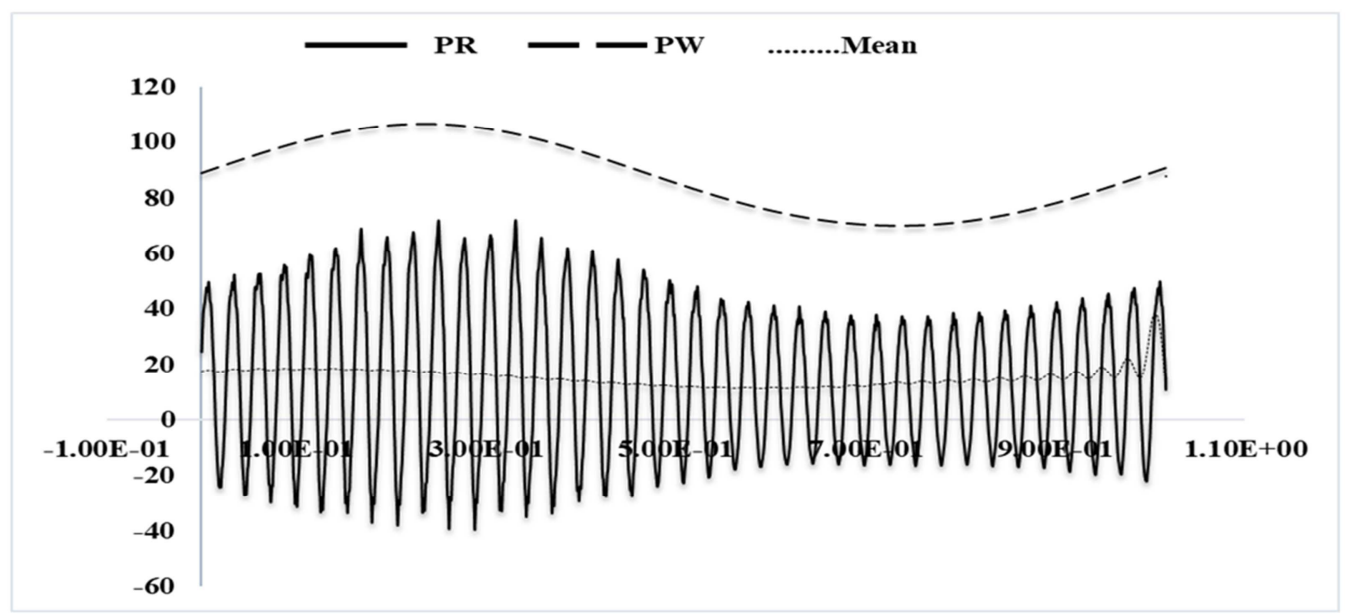

(e). $100 \mathrm{~m}$ turbine hub height

Figure 6. Power performance $\left(P_{R}\right.$ and $\left.P_{W}\right)$ at different turbine hub heights. (show plotting Power $(W)$ versus Time (s)).

Figure 6 is a plot of numerical power performances $\left(\mathrm{P}_{R}\right.$, and $\mathrm{P}_{\mathrm{w}}$ ) across the five turbine hub height elevations for Kiseveni. The available power increases with rising freestream velocity $U_{\infty}$ up to the maximum peak values generated within the first half cycle of the wind cycle at all turbine hub heights, thereafter, it drops to its minimum value at all turbine hub height elevations in the second half of the wind cycle. The findings are in agreement with the previous studies by the authors in Wekesa et al. [7, 8]. The Rotor average power $\mathrm{P}_{\mathrm{R}}$ is obtained from computing average of instantaneous rotor power for the three rotor blades over the periodic wind cycle at each turbine hub height elevation. [8].

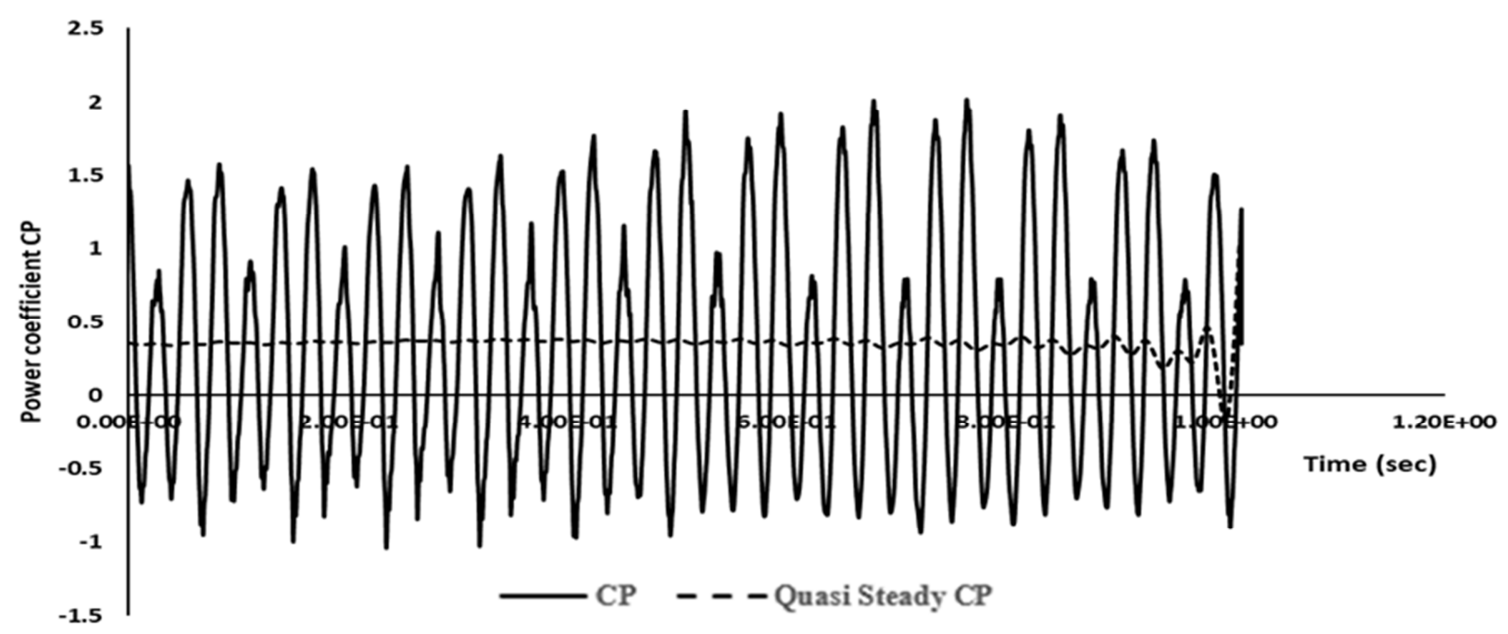

(a). $20 \mathrm{~m}$ turbine hub height

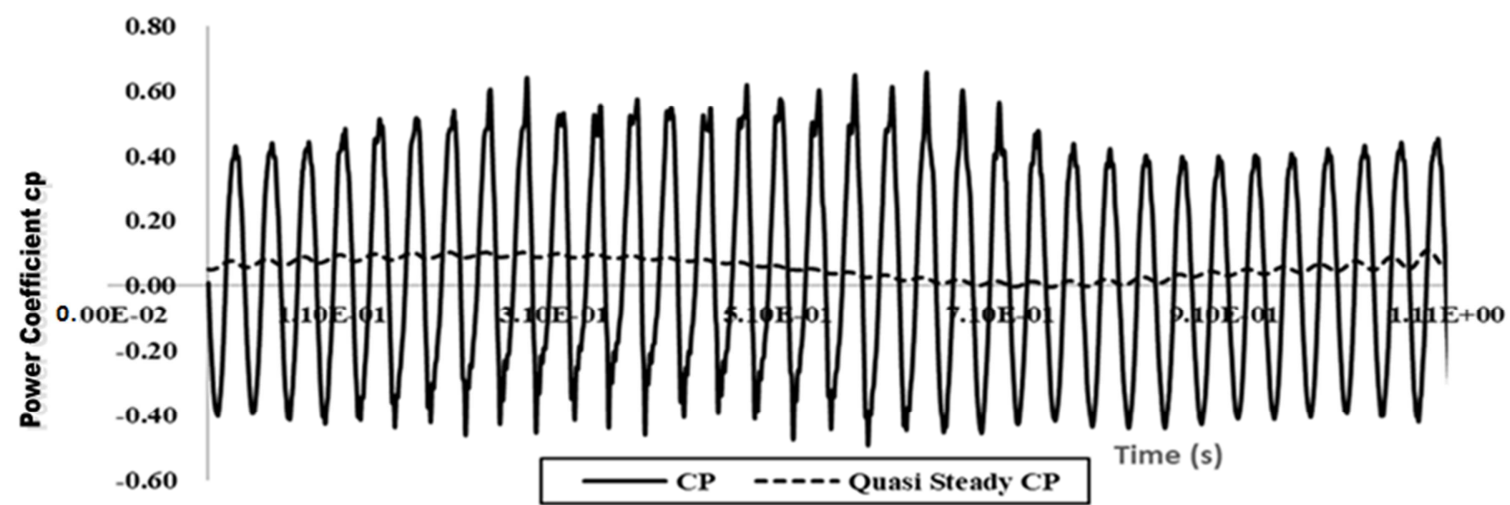

(b). $40 \mathrm{~m}$ turbine hub height 


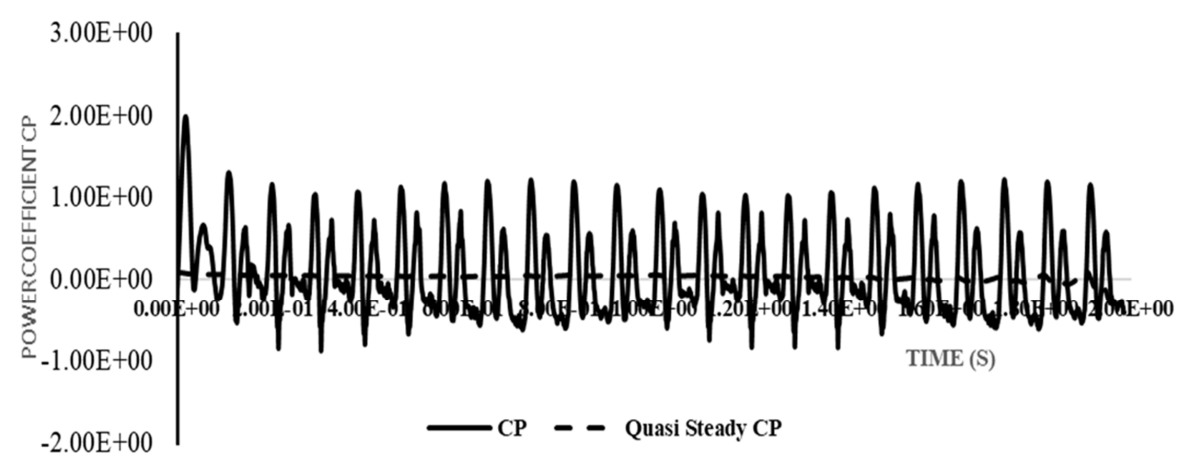

(c). $60 \mathrm{~m}$ turbine hub height

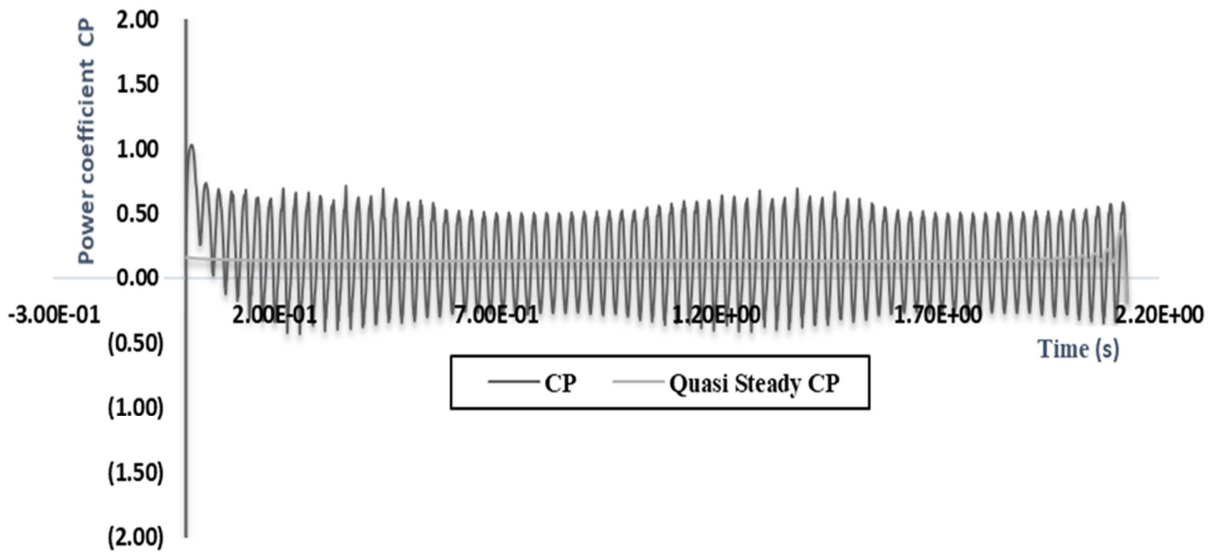

(d). $80 \mathrm{~m}$ turbine hub height

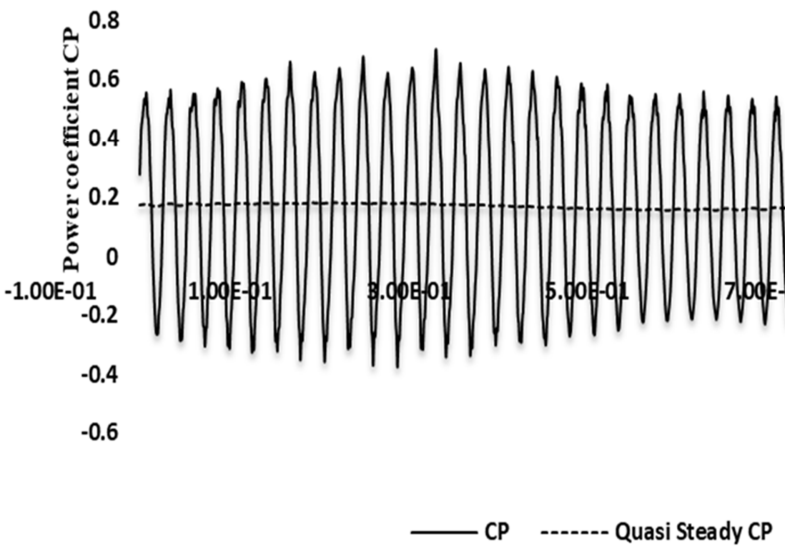

(e). $100 \mathrm{~m}$ turbine hub height

Figure 7. Power coefficient at different hub heights. (show plotting Power (W) versus Time (s)).

Observe in Figure 7 that, unsteady plateau wind CP and quasi-steady $\mathrm{CP}$ are presented using moving average smoothing method as the wind fluctuates at various turbine elevations. Smoothing is found to be consistent with the cycle-averaged method of computing for the rotor $\mathrm{CP}$ in steady wind conditions $[8,11,13]$. This allows a single value prediction of SWT operation performance as a result of filtering the fluctuating nature of the blade torque. From Table 1, unsteady CP is revealed in more detail in Figure 7 where the quasi-steady positive $\mathrm{CP}$ is registered across the turbine hub heights. The results agree to an empirical study by Mukulo et al. [1] and Wekesa et al. [8] at similar site where positive wind performance was projected at hub heights above $40 \mathrm{~m}$. Following the low wind power density values (Table 2), 48.16 to $125.48 \mathrm{~W} / \mathrm{m}^{2}$ between turbine hub heights 20 and $100 \mathrm{~m}$, the plateau region corresponds to wind class 1 . Similar details on wind power classification were revealed by Kamau et al. [15] and National Renewable Energy Laboratory (NREL) [16] where wind power class 1 represented WPD range between 0 and $200 \mathrm{~W} / \mathrm{m}^{2}$ at 50 $\mathrm{m}$ turbine hub height elevation. As a result, the site is considered suitable for small-scale power generation but unsuitable for grid connected power generation. From Wekesa et al. [1], it is worth noting that, the wind speed calculations at very high turbines, 20-100 $\mathrm{m}$ is performed to specifically show CFD approach in 
addressing SWT performance and its added value with respect to the empirical approach, rather than exploring the site's suitability based on the SWT used.

\section{Conclusion}

The results of the study show that the region possess moderate wind resource power which can be used to power the remote area. The power is found to be sufficient to run off grid small wind turbine generators (SWTG) to provide modular electric power to the region. The projected average wind speed at turbine hub heights $40 \mathrm{~m}, 60 \mathrm{~m}, 80 \mathrm{~m}$, and 100 $\mathrm{m}$ were found to be all above cut in threshold of $3.5 \mathrm{~m} / \mathrm{s}$ for a small wind turbine. Having carried out both empirical and numerical analysis of wind resource in the area, this study in no doubt provides a more reliable findings of the wind resource in the area. Both empirical and numerical power densities reveal similar variations across all turbine hub heights with that of numerical analysis being slightly higher since it is less prone to statistical errors. Empirical power density ranged between $31.65 \mathrm{~W} / \mathrm{m}^{2}$ to $54.00 \mathrm{~W} / \mathrm{m}^{2}$ between $40 \mathrm{~m}$ and $100 \mathrm{~m}$ respectively with corresponding numerical power density ranging between $71.76 \mathrm{~W} / \mathrm{m}^{2}$ and 125.45 $\mathrm{W} / \mathrm{m}^{2}$. Numerical $\mathrm{P}_{\mathrm{R}}$ and $\mathrm{P}_{\mathrm{W}}$ were found to be -0.26 and 33.71 at $20 \mathrm{~m}$ hub height giving a negative $\mathrm{CP}$ for the height. The site was found to have a power density which corresponds to wind class 1 meaning the wind resource in the area is not suitable for grid connected generation.

\section{Acknowledgements}

First I wish to pass my acknowledgements to my supervisors Prof. Kamau Joseph and Dr. David Wekesa for their advice throughout the research exercise, their encouragements and consistent monitoring. Special gratitude goes to National Research Fund (Kenya; Grant No. NRF/1/MMC/450) and Department of Physics at Jomo Kenyatta University of Agriculture and Technology (JKUAT) in collaboration with Department of Physics, Machakos University for accepting to fund my research work. Finally I thank my almighty God for the strength He has given me throughout the exercise.

\section{References}

[1] D. W. Wekesa, C. wang, Y. wei, empirical and numerical analysis of small wind turbine aerodynamic performance at a plateau terrain in kitui county.

[2] B. Mukulo, J. Ngaruiya, J. Kamau, Determination of wind energy potential in the Mwingi-Kitui plateau of Kenya, Renew. Energy 63 (2014) 18-22.

[3] Kenya National Bureau of Statistics, Energy Use in Kitui County, 2009, National population census report, 2010.
[4] Kamau, J. N., 2010: Determination of wind power parameters for the assessment of the wind energy potential for selected sites in Kenya. PHD thesis, JKUAT, march 2010.

[5] D. W. Wekesa, C. Wang, Y. Wei, L. A. M. Danao, Influence of operating conditions on unsteady wind performance of vertical axis wind turbines operating within a fluctuating free-stream: a numerical study, J. Wind Eng. Ind. Aerod. 135 (2014) 76-89.

[6] D. W. Wekesa, C. Wang, Y. Wei, J. N. Kamau, L. A. M. Danao, A numerical analysis of unsteady inflow wind for site specific vertical axis wind turbine: a case study for Marsabit and Garissa in Kenya, Renew. Energy 76 (2015) 32-45.

[7] L. A. Danao, J. Edwards, O. Eboibi, R. Howell, A numerical investigation into the influence of unsteady wind on the performance and aerodynamics of a vertical axis wind turbine, Appl. Energy 116 (2014) 111-124.

[8] L. A. Danao, O. Eboibi, R. Howell, An experimental investigation into the influence of unsteady wind on the performance of a vertical axis wind turbine, Appl. Energy 107 (2013) 403-411.

[9] J. M. Edwards, L. A. Danao, R. J. Howell, Novel experimental power curve determination and computational methods for the performance analysis of vertical axis wind turbines, J. Sol. Energy Eng. 134 (2012) 031008.

[10] S. McTavish, D. Feszty, T. Sankar, Steady and rotating computational fluid dynamics simulations of a novel vertical axis wind turbine for small-scale power generation, Renew. Energy 41 (2012) 171e179. scale horizontal axis wind turbine, Energy 65 (2014) 412-418.

[11] D. W. Wekesa, C. Wang, Y. Wei, J. N. Kamau, Wind resource assessment and numerical simulation for wind turbine airfoils, in: 2014 15th International Workshop on Research and Education in Mechatronics (REM), Egypt, vol. 15, IEEE, 2014, pp. 1e9.

[12] D. W. Wekesa, J. N. Mutuku, J. N. Kamau, Microcontrollerbased data logging instrumentation system for wind speed and direction measurements, J. Agric. Sci. Technol. 14 (2012) 176-189.

[13] R. Nobile, M. Vahdati, J. F. Barlow, A. Mewburn-Crook, Unsteady flow simulation of a vertical axis augmented wind turbine: a two-dimensional study, J. Wind Eng. Ind. Aerod. 125 (2014) 168-179.

[14] S. Mcintosh, Wind Energy for the Built Environment, $\mathrm{PhD}$ Thesis, Department of Engineering, Cambridge University, 2009, pp. 105-106, 164.

[15] J. Kamau, R. Kinyua, J. Gathua, 6 years of wind data for Marsabit, Kenya average over $14 \mathrm{~m} / \mathrm{s}$ at $100 \mathrm{~m}$ hub height; an analysis of the wind energy potential, Renew. Energy 35 (2010) 1298-1302.

[16] National Renewable Energy Laboratory (NREL), Wind Data Details: http:// www.nrel.gov/gis/wind_detail.html, (accessed 20.10.2018 at $1230 \mathrm{hrs}$ EAT). 